AGRITECH, Vol. 36, No. 3, Agustus 2016, 308-316

\title{
Evaluation of Major Fatty Acids Determination in Palm Oil by Gas Chromatography-Flame Ionization Detection
}

\author{
Moh. Taufik ${ }^{1,3}$, Hanifah Nuryani Lioe ${ }^{2}$, Nancy Dewi Yuliana² \\ ${ }^{1}$ Food Science Study Program, Bogor Agricultural University, IPB Darmaga Campus, Bogor 16680, Indonesia \\ ${ }^{2}$ Department of Food Science and Technology, Faculty of Agricultural Technology and Enginering, Bogor Agricultural \\ University, IPB Darmaga Campus, PO Box 220, Bogor, 16680, Indonesia \\ ${ }^{3}$ Department of Food Science and Technology, Faculty of Bioindustry, Trilogi University, Jl. TMP. Kalibata No. 1, Jakarta \\ Selatan, Daerah Khusus Ibukota Jakarta 12760, Indonesia \\ E-mail: hanilioe@hotmail.com
}

Submisi: 19 Mei 2015; Penerimaan: 8 September 2015

\begin{abstract}
The fatty acid composition of palm oil is the major factor influencing its physical and chemical properties. The purpose of this research was to evaluate the analytical performance of major fatty acids (palmitic acid, stearic acid, oleic acid, and linoleic acid) analysis in palm oil. Triglycerides of palm oil were derivatized to fatty acid methyl esters (FAMEs) by using boron trifluoride $\left(\mathrm{BF}_{3}\right)$ in methanol. FAMEs were determined by gas chromatography-flame ionization detection (GC-FID) using DB-23 capillary column as stationary phase. The studied parameters were instrument performance analysis, the efficiency of fatty acid derivatization, stability of derivatized analytes, accuracy, repeatability, intra-lab reproducibility, ruggedness, and method uncertainty. The evaluation results showed the instrument linearity at a working range of 5 to $40 \mathrm{mg} / \mathrm{mL}$ marked by coefficient of determination $\left(R^{2}\right)$ between $0.991-0.995$. Instrument limits of detection (LOD) and instrument limits of quantification (LOQ) for 4 major fatty acids analysis were $26-35 \mu \mathrm{g} / \mathrm{mL}$ and $86-128$ $\mu \mathrm{g} / \mathrm{mL}$, respectively. The increase of fatty acid concentration led to the decrease of derivatization efficiency in the fatty acids analysis. The result also showed that derivatized analytes were stable during $24 \mathrm{~h}$ storage at freeze temperature. The average recovery values by spiking method with the spiking concentration at 50 and $90 \mathrm{mg} / \mathrm{g}$ sample were at $75-94$ $\%$ for stearic and linoleic acids analysis, however those for palmitic and oleic acids analysis were considered very low $(<40 \%)$, due to their low derivatization efficiency. Repeatability and intra-lab reproducibility of 4 major fatty acids analysis were at acceptable ranges, $0.45-1.38 \%$ and $1.15-2.03 \%$, respectively. Determination by varying the volume of derivatizing agent showed the rugged method. Uncertainty of repeatability $\left(U_{r}\right)$ and uncertainty of reproducibility $\left(U_{r}\right)$ were ranged at $1.84-9.02 \mathrm{mg} / \mathrm{g}$ and $1.40-10.65 \mathrm{mg} / \mathrm{g}$, respectively. This method was considerably reliable for the analysis of less abundance fatty acids in palm oil, stearic and linoleic acids.
\end{abstract}

Keywords: Analytical evaluation; fatty acid analysis; palm oil; gas chromatography-flame ionization detection; fatty acid derivatization

\section{INTRODUCTION}

Vegetable oils play an important role in the functional and sensorial properties of food and also have a function as carrier for fat soluble vitamins (Moreira et al., 1999). The composition of fatty acids affects the physical and chemical characteristic of the oil (Knothe and Kenar, 2004). One of the important vegetable oils is palm oil. According to Gunstone
(2011), palm oil is consumed in many countries and also produced in the greatest amount. The major fatty acids in palm oil reported by Sundram et al. (2003), Gee (2007), Kumar and Krishna (2014) were palmitic acid (43.5\%, $44.1 \%$ and $41.8 \%$ ), oleic acid $(39.8 \%, 39.0 \%$ and $37.4 \%$ ), linoleic acid $(10.2 \%, 10.6 \%$ and $14.1 \%)$ and stearic acid (4.3\%, $4.4 \%$ and $3.5 \%)$. 
Data of fatty acid composition is very important for food scientist and nutritionist to develop dietary formulation, food processing and new product (Muhamad and Mohamad, 2012). Furthermore, data of fatty acid composition can also be used to create nutrition facts of the product, especially to provide the facts of total saturated and unsaturated fat composition. Several methods have been introduced to determine the fatty acid composition of vegetable and animal oils. The most widely used technique to analyze the fatty acid composition is gas chromatography coupled with flame ionization detector (GC-FID) (Martínez et al., 2009). The flame ionization detection is adequate for analytical applications of fatty acids (Petrovic et al., 2010). This technique based on the AOAC Official Method 991.39 (AOAC, 2012). This official method basically provides clear guidelines for analyzing the fatty acid composition in fish oils.

Lipids must be converted into fatty acid methyl esters (FAMEs) to achieve their volatility for GC analysis. There are many different derivatization methods in literature. The commonly used derivatization method in the analysis of fatty acids involves basic and acid catalysis. One of the basic catalysts commonly used in the derivatization of triacylglycerol is sodium methoxide $\left(\mathrm{NaOCH}_{3}\right)$ in methanol (Milinsk et al., 2008). Derivatization by using $\mathrm{NaOCH}_{3}$ in methanol can be implemented at room temperature in a short time (Macedo et al., 2012), but the basic catalyst cannot transform free fatty acids into FAMEs including free fatty acids used as internal standard (Ichihara and Fukubayashi, 2010). Boron trifluoride $\left(\mathrm{BF}_{3}\right)$ in methanol is one of the most commonly used acid catalysts as a derivatizing agent because this catalyst has high esterifying power (Liu, 1994). $\mathrm{BF}_{3}$ can catalyze the methylation of fatty acids in both free and esterified forms in the presence of methanol (Wirasnita et al., 2013). According to Knapp (1979), derivatization triglycerides to be FAMEs by using acid catalyst can be divided in two steps i.e. saponification and esterification reaction. $\mathrm{BF}_{3}$ can accelerate the esterification reaction between the salt of corresponding fatty acid and methanol.

Many researchers have studied about the evaluation of fatty acid analysis in some products. Omar and Salimon (2013) evaluated the fatty acid analysis in bakery products by using GC-FID and $\mathrm{NaOCH}_{3}$ as catalyst. The results of Omar and Salimon (2013) showed that linearity for palmitic acid, oleic acid and linoleic acid analysis at concentration of 0.1 to $24 \mu \mathrm{g} / \mathrm{mL}$ ranged from 0.993 to 0.998 , while the recovery values and repeatability were ranged at 96.83-98.54\% and 0.56-0.71\%, respectively. Tong (2007) studied about palmitic acid, oleic acid and linoleic acid analysis in Periploca sepium using GC-FID and $\mathrm{BF}_{3}$ in ether as catalyst. Tong et al. (2007) found that the recovery values were ranged at 99.2-100.2\%, while repeatability ranged from $0.5 \%$ to $0.7 \%$.
According to AOAC Official Method 991.39 (AOAC, 2012), the amount of sample to be analyzed was $25 \mathrm{mg}$, while the volume of $\mathrm{BF}_{3-}$ methanolic $(12 \% \mathrm{w} / \mathrm{v})$ used was $2.0 \mathrm{~mL}$. In fact, increasing the amount of sample will impact the improving of detectability of gas chromatography to the smallest concentration compound in sample (Orata, 2012). Parashar et al. (2009) used $200 \mathrm{mg}$ of initial sample and $4.4 \mathrm{~mL}$ of $\mathrm{BF}_{3}$ in ether to analyze the fatty acid composition of pomegranate oil. Wirasnita et al. (2013) used $350 \mathrm{mg}$ of sample and $7 \mathrm{~mL}$ of $\mathrm{BF}_{3-}$ methanol $(12 \%, \mathrm{w} / \mathrm{v})$ to analyze the fatty acid composition of pumpkins oil. Tong et al. (2007) used $100 \mathrm{mg}$ of initial sample and $2.0 \mathrm{ml}$ of $\mathrm{BF}_{3}$ in ether to analyze the fatty acid composition of Periploca sepium.

The objective of this research was to provide the analytical performance of major fatty acids analysis in palm oil using $\mathrm{BF}_{3}$ in methanol for derivatization and GC-FID for determination. The analysis was performed at $100 \mathrm{mg}$ sample weight. The parameters studied were chromatographic precision, instrument linearity, instrument limit of detection (LOD), instrument limit of quantification (LOQ), the efficiency of fatty acid derivatization, stability of derivatized analytes, accuracy, repeatability, intra-lab reproducibility, ruggedness, and method uncertainty.

\section{MATERIALS AND METHODS}

\section{Materials}

Palm oil was purchased from local market in Bogor, Indonesia. Palmitic acid (minimum purity $99 \%$ ), stearic acid (purity approximately $99 \%$ ), oleic acid (purity approximately $95 \%$ ), linoleic acid (purity approximately $\geq$ $99 \%$ ) and margaric acid (purity approximately $99 \%$ ) were purchased from Sigma-Aldrich (Steinheim, Germany). External standard (FAME Mix C8-C22) was purchased from Supelco (Bellefonte, US). Hexane, p.a., $\mathrm{Na}_{2} \mathrm{SO}_{4}$ anhydrous, p.a., $\mathrm{NaOH}, \mathrm{NaCl}$ and methanol were purchased from Merck (Darmstadt, Germany). $\mathrm{BF}_{3}$ in methanol (14\%, wt/vol) was purchased from Merck (Hohenbrunn, Germany).

\section{Fatty Acids Analysis in Palm Oil}

\section{Derivatization}

The derivatization was conducted following the procedure described by AOAC Official Method 991.39 (AOAC, 2012), with modification in the amount of initial sample, the kind of extracting solvent and the temperature of heating. Approximately $100 \mathrm{mg}$ of palm oil was placed into a screw cap glass tube. As much as $0.1 \mathrm{~mL}$ of margaric acid solution $(10 \mathrm{mg} / \mathrm{mL})$ as internal standard and $1.5 \mathrm{~mL}$ of $\mathrm{NaOH}$ in methanol $(0.5 \mathrm{~N})$ were added into the tube and then nitrogen 
was blown for 15 seconds to the tube. The tube was covered tightly, vortexed with a vortex 16700 Mixer Thermolyne (Maxi-Mix 1, Lowa, US), heated in a water bath W350 Memmert (Memmert GmbH and Co, Schwabach, Germany) for 5 minutes at $87{ }^{\circ} \mathrm{C}$ and then cooled. Furthermore, the tube was added by $2 \mathrm{~mL}$ of $\mathrm{BF}_{3}$ in methanol (14\%, wt/vol), vortexed and then nitrogen was blown to the tube. The tube was covered tightly, heated for 30 minutes at $87^{\circ} \mathrm{C}$ and then cooled. In this stage, fatty acids were converted to fatty acid methyl esters (FAMEs). Extracting solvent, $1 \mathrm{~mL}$ of hexane, was added and then the mix was vortexed. Furthermore, 3 $\mathrm{mL}$ of saturated $\mathrm{NaCl}$ solution was added and then the mix solution was vortexed. Upper phase was transferred into the vial. $\mathrm{Na}_{2} \mathrm{SO}_{4}$ anhydrous was added into the vial to absorb moisture.

\section{GC Analysis}

FAMEs from external standard or FAMEs resulted from sample derivatization were injected separately into Gas Chromatography instrument (GC). The GC analyses were performed on 7890A Gas Chromatography System (Agilent Technologies, California, US) equipped with flame ionization detector and splitless injector $(1 \mu \mathrm{L})$. Injector and detector temperature were set at $270{ }^{\circ} \mathrm{C}$ and $280{ }^{\circ} \mathrm{C}$, respectively. The utilized column was a DB-23 $(60 \mathrm{~m} \times 0.25 \mathrm{~mm}$, with film thickness of $0.25 \mu \mathrm{m})$. This column was purchased from $\mathrm{J}$ and W Scientific (Folsom, CA). The GC oven program was as follows: $130{ }^{\circ} \mathrm{C}$ (hold $2 \mathrm{~min}$ ), to $170{ }^{\circ} \mathrm{C}$ at $6.5^{\circ} \mathrm{C} / \mathrm{min}$ (hold $5 \mathrm{~min}$ ), to $215^{\circ} \mathrm{C}$ at $2.75^{\circ} \mathrm{C} / \mathrm{min}$ (hold $12 \mathrm{~min}$ ), to $230^{\circ} \mathrm{C}$ at $30{ }^{\circ} \mathrm{C} / \mathrm{min}$ (hold $30 \mathrm{~min}$ ). Helium and nitrogen of ultrahigh purity grade were used as carrier gases at flow rates of 11.07 and $31.24 \mathrm{~mL} / \mathrm{min}$.

\section{Identification and Concentration of Fatty Acid}

The fatty acid identification was determined by comparing retention time of the peaks with the respective external standards. The concentration of fatty acids was calculated with the following equation (AOAC, 2012).

$$
[\mathrm{ALx}]=\frac{\text { Aalxs }}{\mathrm{ASIs}} \times \frac{[\mathrm{BSIs}]}{\mathrm{BS}} \times \frac{\text { ASle }}{\text { Aalxe }} \times \frac{[\text { Balxe }]}{\lceil\text { BSIe }]} \times 1000
$$

Where:

$[\mathrm{ALx}]=$ Concentration of fatty acid $\mathrm{X}$ on sample $(\mathrm{mg} / \mathrm{g})$

Aalxs = Area of fatty acid X on chromatogram of sample

ASIs = Area of margaric acid (internal standard) on chromatogram of sample

[BSIs] = Concentration of margaric acid (internal standard) on sample

BS $\quad=$ Weigh of sample $(\mathrm{mg})$
ASIe = Area of margaric acid (internal standard) on chromatogram of external standard

Aalxe $=$ Area of fatty acid $\mathrm{X}$ on chromatogram of external standard

[Balxe $]=$ Concentration of fatty acid X on external standard

[BSIe] = Concentration of margaric acid (internal standard) on external standard

\section{Instrument Performance Analysis}

Instrument performance analysis included chromatographic precision, instrument linearity, instrument limit of quantification (LOQ) and instrument limit of detection (LOD). The chromatographic precision was examined by following the method described by Ping (2013) i.e. using Coefficient of Variation (CV) of retention time and peak area from the injection multiple times. In this study, the chromatographic precision was determined by analysing seven replicates of $1 \mathrm{~mL}$ a fatty acid mix standard solution containing palmitic, stearic, oleic and linoleic acids at concentration of each fatty acid of $10 \mathrm{mg} / \mathrm{mL}$ in hexane solution. The chromatographic precision was expressed as $\mathrm{CV}(\%)$ of retention time and peak area of every fatty acid in the mix solution as observed in their chromatogram. The $\mathrm{CV}$ of retention time and peak area was calculated with the following equation.

$$
\mathrm{CV}=\frac{\mathrm{SD}}{\bar{x}} \times 100 \%
$$

Where:

$\mathrm{CV}=$ Coefficient of Variation $(\%)$

$\mathrm{SD}=$ Standard deviation of retention time or peak area

$\bar{x}=$ Mean value of retention time or peak area

The instrument linearity was evaluated through a calibration curve by making a plot between peak area ratios of each fatty acid to internal standard versus the corresponding fatty acid concentration. The serial concentration of each fatty acid in fatty acids mix standard solutions were 5, 10, 20,30 and $40 \mathrm{mg} / \mathrm{mL}$. The fatty acid mix standard solutions, containing palmitic, stearic, oleic and linoleic acids, were analyzed as much as $1 \mathrm{~mL}$ in duplicate. The instrument linearity was observed by determining the coefficient of determination $\left(\mathrm{R}^{2}\right)$.

LOD and LOQ were determined from the standard deviation (SD) of seven determinations at a low concentration of fatty acid mix standard solution at concentration of each fatty acid of $10 \mathrm{mg} / \mathrm{mL}$. The fatty acid mix standard solution, containing palmitic, stearic, oleic and linoleic acids, was analyzed as much as $1 \mathrm{~mL}$. LOD was calculated as $3 \mathrm{SD}$, while LOQ was calculated as 3.3 LOD (Squadrone et al., 2010). 


\section{The Efficiency of Fatty Acid Derivatization}

The efficiency of fatty acid derivatization was evaluated using fatty acids mix standard solutions at four concentrations of each fatty acid, i.e. 10, 20, 30 and $40 \mathrm{mg} / \mathrm{mL}$. One $\mathrm{mL}$ of each fatty acids mix standard solution, containing palmitic, stearic, oleic and linoleic acids, was analyzed in duplicate. The efficiency of each fatty acid derivatization by $\mathrm{BF}_{3}$ methanol was determined from its respective recovery value. Recovery values can be calculated by dividing the obtained concentrations to the true concentrations of fatty acid (Kazusaki et al., 2012).

\section{Stability of Derivatized Analytes}

The stability of derivatized analytes stored at freeze temperature $\left(-10 \pm 2{ }^{\circ} \mathrm{C}\right)$ prior to $\mathrm{GC}$ injection was examined by following the method described by Petrovic et al. (2010) i.e. analyzing derivatized analytes during a certain period. The determination of derivatized analytes resulted from palm oil derivatization was performed at 0 and $24 \mathrm{~h}$ after storage. This analysis was done in duplicate. Statistical analysis by t-test was performed to determine the stability of derivatized analytes stored at the freeze temperature.

\section{Evaluation of Analytical Method}

\section{Accuracy and repeatability}

The accuracy was determined by recovery test. The spiking method using palm oil sample $(100 \mathrm{mg})$ at spiking concentrations of 50 and $90 \mathrm{mg}$ fatty acid/g palm oil was performed. The samples were analyzed in five replicates for spiked sample and duplicate for non-spiked sample. Repeatability was expressed as relative CV (\%) from spiked sample, while accuracy was calculated as recovery (AOAC 2012).

\section{Intra-lab reproducibility}

Intra-lab reproducibility was evaluated by analyzing palm oil with the same instrument, same operator but at three different months. The replication of each analysis was done in duplicate. Intralab reproducibility was expressed as CV (\%).

\section{Ruggedness}

According to AOAC (2012), the volume of $\mathrm{BF}_{3}$ in methanol used in fatty acid derivatization was $2.0 \mathrm{~mL}$. In this study, ruggedness of the method was evaluated by varying the volume of $\mathrm{BF}_{3}$ in methanol (14\%, wt/vol) i.e 1.8, 2.0 and 2.2 $\mathrm{mL}$. Palm oil was used for this analysis. Each analysis was done in duplicate. Statistical analysis by one-way ANOVA was performed to determine the ruggedness of this method.

\section{Uncertainty of Repeatability $\left(U_{r}\right)$ and Uncertainty of Reproducibility $\left(\mathrm{U}_{\mathrm{R}}\right)$}

The calculation of $U_{r}$ and $U_{R}$ followed Česnik and Gregorčič (2006). $U_{r}$ and $U_{R}$ were determined with the following equation

$\mathrm{U}_{\mathrm{r}}=\mathrm{t}_{95: 9} \times \mathrm{SD}_{\mathrm{r}} ; \mathrm{U}_{\mathrm{R}}=\mathrm{t}_{95: 9} \times \mathrm{SD}_{\mathrm{R}}$

Where:

$\mathrm{SD}_{\mathrm{r}}=$ standard deviation of repeatability,

$\mathrm{SD}_{\mathrm{R}}=$ standard deviation of intra-lab reproducibility and

$\mathrm{t}_{95: 9}=$ student's $\mathrm{t}$ factor for 9 degrees of freedom and $95 \%$ confidence level $\left(\mathrm{t}_{95: 9}=2.262\right)$

\section{RESULTS AND DISCUSSION}

\section{Instrument Performance Analysis}

Chromatographic precision shows the stability of gas chromatography-flame ionization detector (GC-FID) with certain conditions and parameters in detecting fatty acids. The chromatographic precision of retention time and peak area for palmitic acid, stearic acid, oleic acid and linoleic acid are presented in Table 1. CV of retention time and peak area for palmitic acid and stearic acid of this result is comparable to that performed by Ping (2013) i.e. 0.03-0.09\% for retention time and $0.21-1.55 \%$ for peak area. $\mathrm{CV}$ of retention time

Table 1. Precision of retention time and peak area in fatty acids analysis by GC-FID with $\mathrm{BF}_{3}$-methanol derivatization, evaluated from 7 determinations of fatty acids at low concentration

\begin{tabular}{lcccc}
\hline & $\begin{array}{c}\text { Concentration } \\
\text { Fatty acid }\end{array}$ & \multicolumn{2}{c}{ Average } & \multicolumn{2}{c}{ CV $(\%)$} \\
\cline { 3 - 5 } & & Retention time (min) & Peak area & $\begin{array}{c}\text { Retention time } \\
\text { area }\end{array}$ \\
\hline Margaric acid (C17:0) & 10 & $39.251 \pm 0.030$ & $437.08 \pm 7.12$ & 0.08 \\
Palmitic acid (C16:0) & 10 & $35.777 \pm 0.024$ & $3940.91 \pm 65.11$ & 0.07 \\
Stearic acid (C18:0) & 10 & $43.114 \pm 0.051$ & $4040.24 \pm 66.64$ & 0.12 \\
Oleic acid (C18:1) & 10 & $44.413 \pm 0.039$ & $4245.42 \pm 69.72$ & 0.09 \\
Linoleic acid (C18:2) & 10 & $46.831 \pm 0.040$ & $4355.91 \pm 72.84$ & 1.65 \\
\hline
\end{tabular}


and peak area was also lower than $2.0 \%$. Maximum CV for chromatographic precision is $2.0 \%$ (JECFA, 2006). This result indicated that the GC-FID with conditions and parameters used was stable in detecting fatty acids.

Instrument linearity is the ability of analytical methods to show a proportional response to the concentration of analyte at a given range (Kazusaki et al., 2012). Instrument linearity was verified at range of fatty acid concentration from 5 to 40 $\mathrm{mg} / \mathrm{mL}$. The results of instrument linearity for palmitic acid, stearic acid, oleic acid and palmitic acid are shown in Table 2. Obtained results showed that the determination coefficient $\left(\mathrm{R}^{2}\right)$ values for all fatty acids were acceptable. A linear regression with an $\mathrm{R}^{2}$ value $>0.990$ is a very good fit (AOAC, 2012).Instrument limit of detection (LOD) is the lowest concentration of the analyte in standard solution that can be detected but not necessarily quantified, while instrument limit of quantification (LOQ) is the lowest concentration of the analyte in standard solution that can be quantified with acceptable precision. LOD and LOQ of this research can be seen in Table 3. LOQ of this result is comparable to that performed by Tong et al. (2007) i.e. LOQ at a range of 19-87 $\mu \mathrm{g} / \mathrm{mL}$. Tong et al. (2007) validated a method to determine fatty acid composition in vegetable oil by GC-FID with $\mathrm{BF}_{3}$-methanol derivatization. In derivatization step, Tong et al. (2007) used the larger $\mathrm{NaOH}-m e t h a n o l$ volume and the shorter reaction time i.e. $5 \mathrm{~mL}$ and $5 \mathrm{~min}$, respectively. According to Wang (2008), LOD and LOQ values are affected by physicochemical properties of the analytes, methods used and instrumental parameter.

Table 2. Result of instrument linearity of fatty acids analysis by GC-FID with $\mathrm{BF}_{3}$-methanol derivatization $(\mathrm{N}=2)$

\begin{tabular}{lcc}
\hline Fatty acid & Regression equation & $\mathrm{R}^{2}$ \\
\hline Palmitic acid (C16:0) & $y=4.109 x+0.070$ & 0.994 \\
Stearic acid (C18:0) & $y=4.072 x-0.123$ & 0.995 \\
Oleic acid (C18:1) & $y=3.827 x+0.130$ & 0.991 \\
Linoleic acid (C18:2) & $y=5.186 x-0.010$ & 0.993 \\
\hline
\end{tabular}

Table 3. LOD and LOQ of fatty acids analysis by GCFID with $\mathrm{BF}_{3}-$ methanol derivatization from determined by 7 determinations of fatty acids at low concentration

\begin{tabular}{lcc}
\hline Fatty acid & $\begin{array}{c}\text { Instrument limit of } \\
\text { detection }(\mathrm{LOD}) \\
(\mu \mathrm{g} / \mathrm{mL})\end{array}$ & $\begin{array}{c}\text { Instrument limit } \\
\text { of quantification } \\
(\mathrm{LOQ})(\mu \mathrm{g} / \mathrm{mL})\end{array}$ \\
\hline Palmitic acid (C16:0) & 26 & 86 \\
Stearic acid (C18:0) & 35 & 116 \\
Oleic acid (C18:1) & 27 & 89 \\
Linoleic acid (C18:2) & 38 & 128 \\
\hline
\end{tabular}

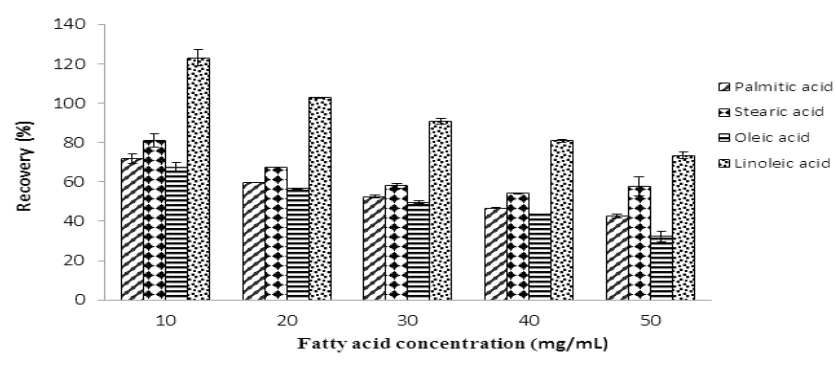

Figure 1. The efficiency of fatty acid derivatization by $\mathrm{BF}_{3}$-methanol in fatty acids analysis by GC-FID at different concentrations of fatty acids in the mix standard solution.

\section{The Efficiency of Fatty Acid Derivatization}

The efficiency of fatty acid derivatization indicates the percentage of fatty acid in sample which can be derivatized by derivatizing agent and detected by GC-FID instrument. The efficiency of derivatization can be predicted by the recovery value of fatty acid standard analysis. The efficiency of derivatization for palmitic acid, stearic acid, oleic acid and linoleic acid analyses at four concentrations are shown in Figure 1. In this study, it is revealed that at the same concentration of 4 fatty acids, the efficiency of derivatization was different to each other.

The derivatization efficiency showed by recovery values was higher for stearic and linoleic acids (averaged 65.2-99.5\%), however for palmitic and oleic acids gave lower efficiency (averaged 54.3-57.7 \%). The low recovery might be affected by the shorter reaction time, lower reaction temperature and methanol volume used in derivatization step in this study. Hallmann et al. (2008) analyzed the efficiency of $\mathrm{BF}_{3}$ to derivatize fatty acid into fatty acid butyl ester (FABEs). The research result of Hallmann et al. (2008) showed that the efficiency of fatty acid derivatization can be improved by the increase of reaction time, reaction temperature and methanol volume.

The efficiency of derivatization decreased with the increase of fatty acids concentration to be analyzed. The low recovery for higher concentration of fatty acids might be caused by the insufficient amount of $\mathrm{BF}_{3}$-methanol used in this study. The efficiency of derivatization can be increased by using high volume of catalyst or small amount of sample. Liu (1994) recommended to use small amount of sample in fatty acid derivatization.

\section{Stability of Derivatized Analytes}

According to Paligova et al. (2008), derivatized analytes (FAMEs) have low storage stability due to their high potential to be hydrolyzed and oxidized. However, the stability of the FAMEs during freeze storage $24 \mathrm{~h}$ has been proved to be acceptable as presented in Table 4. 
Table 4. Stability of fatty acid methyl esters (FAMEs) with and without freeze storage $24 \mathrm{~h}$

\begin{tabular}{lcccc}
\hline \multirow{2}{*}{$\begin{array}{l}\text { Freeze } \\
\text { storage }(\mathrm{h})\end{array}$} & $\begin{array}{c}\text { Palmitic acid } \\
(\mathrm{C} 16: 0)\end{array}$ & $\begin{array}{c}\text { Stearic acid } \\
(\mathrm{C} 18: 0)\end{array}$ & $\begin{array}{c}\text { Oleic acid } \\
(\mathrm{C} 18: 1)\end{array}$ & $\begin{array}{c}\text { Linoleic acid } \\
(\mathrm{C} 18: 2)\end{array}$ \\
\hline 0 & $241.6 \pm 0.4$ & $28.1 \pm 0.1$ & $283.0 \pm 0.7$ & $104.0 \pm 0.2$ \\
24 & $240.5 \pm 2.2$ & $28.0 \pm 0.1$ & $281.0 \pm 0.2$ & $102.0 \pm 0.1$ \\
\hline
\end{tabular}

No significant difference in fatty acid concentrations was observed in the analysis of fatty acids in palm oil with and without freeze storage $24 \mathrm{~h}$ of analytes solution after derivatization. This result indicated that FAMEs was stable during $24 \mathrm{~h}$ storage at freeze temperature. According to Ashraful et al. (2014), the main factor affecting FAMEs oxidation is storage temperature. Freeze storage temperature $\left(-6.8 \pm 0.3{ }^{\circ} \mathrm{C}\right)$ was predicted causing the stability of FAMEs during storage. In this study, FAMEs resulted from palm oil derivatization was stored in dark vial. FAME samples stored in dark glass vessels are more stable (Paligova' et al., 2008).

\section{Evaluation of Analytical Method}

\section{Accuracy and repeatability}

Accuracy describes the closeness of the analytical results obtained to the true values of the analyte (Kazusaki et al., 2012). Accuracy was evaluated by recovery experiment at two spiking concentrations. The recovery values of palmitic acid, stearic acid, oleic acid and linoleic acid analysis at two spiking concentrations are summarized in Table 5. These four major fatty acid were totally present at concentration of 687$690 \mathrm{mg} / \mathrm{g}$ in non-spiked palm oil $(\mathrm{N}=4)$.
The averaged recovery values by spiking method at 50 and $90 \mathrm{mg} / \mathrm{g}$ spiking concentration for palmitic acid and oleic acid were very low because the efficiency of $\mathrm{BF}_{3}$-methanol derivatization for these fatty acids at given concentration was also very low (derivatization efficiency: $53 \%$ for palmitic acid and $49 \%$ for oleic acid). The averaged recovery values for stearic acid and linoleic acid analysis were higher. The higher recovery might be resulted from the high efficiency of $\mathrm{BF}_{3}$ in methanol derivatization for stearic acid and linoleic acid at found concentration (81\% for stearic acid and $104 \%$ for linoleic acid).

Repeatability is the variation from multiple analyses of a single homogeneous sample (Kazusaki, 2012). Repeatability was calculated as CV (\%) of fatty acids from spiked sample. $\mathrm{CV}$ resulted from analysis and $\mathrm{CV}$ calculated by Horwitz formula according to AOAC PVM (as an acceptable CV value, 2/3 CV Horwitz) at two spiking concentrations are presented in Table 5. CV analysis from this research was lower than $2 / 3$ CV Horwitz. This result suggested that repeatability of this method was acceptable. The CV values obtained were also lower than the result of Tong et al. (2007). Tong et al. (2007) reported that $\mathrm{CV}$ for palmitic acid, oleic acid and linoleic acid analysis was $2.1,4.4$ and $2.9 \%$, respectively.

\section{Intra-lab Reproducibility}

Intra-laboratory reproducibility indicates the degree of variation from analyses at different time. CV of intralab reproducibility from the results of the major fatty acids analysis in palm oil in three different months can be seen in Table 6.

Table 5. Recovery and repeatability of four fatty acids in palm oil at two spiking concentrations analyzed by GC-FID with BF ${ }_{3}$ methanol derivatization $(\mathrm{N}=5)$

\begin{tabular}{|c|c|c|c|c|c|c|}
\hline \multirow[b]{2}{*}{ Fatty acid } & \multicolumn{3}{|c|}{ Concentration $(\mathrm{mg} / \mathrm{g})$} & \multirow[b]{2}{*}{ Recovery (\%) } & \multicolumn{2}{|c|}{ Repeatability } \\
\hline & Initial & Spiking & Found & & $\begin{array}{c}\mathrm{CV} \\
\text { analysis } \\
(\%)\end{array}$ & $\begin{array}{c}\text { 2/3 CV } \\
\text { Horwitz (\%) }\end{array}$ \\
\hline Palmitic acid (C16:0) & $256.3 \pm 1.5$ & $50.0 \pm 3.2$ & $273.4 \pm 2.2$ & $34.34 \pm 5.60$ & 0.79 & 1.62 \\
\hline Stearic acid (C18:0) & $31.2 \pm 0.1$ & $54.1 \pm 3.4$ & $72.8 \pm 0.8$ & $77.06 \pm 3.91$ & 1.12 & 1.98 \\
\hline Oleic acid (C18:1) & $302.6 \pm 2.1$ & $48.8 \pm 3.1$ & $313.8 \pm 2.9$ & $23.20 \pm 6.60$ & 0.91 & 1.59 \\
\hline Linoleic acid (C18:2) & $110.3 \pm 1.4$ & $49.4 \pm 3.1$ & $155.5 \pm 0.9$ & $93.65 \pm 5.69$ & 0.56 & 1.76 \\
\hline Palmitic acid (C16:0) & $255.6 \pm 1.7$ & $90.0 \pm 3.6$ & $284.8 \pm 1.3$ & $32.47 \pm 2.46$ & 0.45 & 1.61 \\
\hline Stearic acid (C18:0) & $30.34 \pm 0.1$ & $97.4 \pm 3.9$ & $103.0 \pm 1.4$ & $74.68 \pm 1.66$ & 1.38 & 1.88 \\
\hline Oleic acid (C18:1) & $301.6 \pm 2.2$ & $87.9 \pm 3.5$ & $322.8 \pm 3.9$ & $24.24 \pm 4.89$ & 1.24 & 1.58 \\
\hline Linoleic acid (C18:2) & $110.1 \pm 0.6$ & $87.2 \pm 3.5$ & $188.5 \pm 1.9$ & $89.98 \pm 2.00$ & 1.02 & 1.71 \\
\hline
\end{tabular}


Table 6. Intra-lab reproducibility of fatty acids analysis by GC-FID with $\mathrm{BF}_{3}$-methanol derivatization $(\mathrm{N}=2)$

\begin{tabular}{lcccc}
\hline \multirow{2}{*}{ Months } & \multicolumn{4}{c}{ Fatty acid $(\mathrm{mg} / \mathrm{g})$} \\
\cline { 2 - 5 } & $\begin{array}{c}\text { Palmitic acid } \\
(\mathrm{C} 16: 0)\end{array}$ & $\begin{array}{c}\text { Stearic acid } \\
(\mathrm{C} 18: 0)\end{array}$ & $\begin{array}{c}\text { Oleic acid } \\
(\mathrm{C} 18: 1)\end{array}$ & $\begin{array}{c}\text { Linoleic acid } \\
(\mathrm{C} 18: 2)\end{array}$ \\
\hline I & $248.6 \pm 0.6$ & $30.0 \pm 0.1$ & $294.0 \pm 0.7$ & $108.0 \pm 0.4$ \\
II & $256.3 \pm 1.5$ & $31.2 \pm 0.1$ & $302.6 \pm 2.1$ & $110.3 \pm 1.4$ \\
III & $255.6 \pm 1.7$ & $30.3 \pm 0.1$ & $301.6 \pm 2.2$ & $110.1 \pm 0.6$ \\
\hline CV analysis (\%) & 1.68 & 2.03 & 1.57 & 1.15 \\
\hline CV Horwitz (\%) & 2.46 & 3.38 & 2.40 & 2.79 \\
\hline
\end{tabular}

$\mathrm{CV}$ analysis for palmitic acid, stearic acid, oleic acid and linoleic acid analysis ranged from $1.15 \%$ to $2.03 \%$. $\mathrm{CV}$ analysis from this research was lower than CV Horwitz. This result indicated that reproducibility of this method was acceptable at three mounts analysis. The CV values obtained were comparable to other research result as reported by Omar and Salimon (2013) who validated a gas chromatographic method for determining fatty acids in bakery products. They reported that $\mathrm{CV}$ for palmitic acid, oleic acid and linoleic acid analysis ranged from 1.83 to $4.09 \%$.

\section{Ruggedness}

Ruggedness is the ability of a method to not be affected by variation in reagent or procedure analysis. Ruggedness of this method was evaluated by the variation of $\mathrm{BF}_{3}$ volume i.e. $1.8,2.0$ and $2.2 \mathrm{~mL}$. $\mathrm{BF}_{3}$-methanol is a catalyst in this fatty acid analysis.

The analysis results of major fatty acids analysis in palm oil with variation of $\mathrm{BF}_{3}$-methanol volume are given in Table 7. The result of one-way ANOVA showed that the concentration of fatty acids at every treatment was no significant difference. It suggested that derivatization method was rugged to the variation of $\mathrm{BF}_{3}$-methanol volume in the given range $(1.8-2.2 \mathrm{~mL}, 14 \% \mathrm{w} / \mathrm{v})$.

Table 7. Ruggedness of fatty acids analysis by GC-FID with different volumes of $\mathrm{BF}_{3}$-methanol solution for fatty acids derivatization $(\mathrm{N}=2)$

\begin{tabular}{lcccc}
\hline $\begin{array}{l}\mathrm{BF}_{3}- \\
\text { methanol }\end{array}$ & \multicolumn{4}{c}{ Fatty acid $(\mathrm{mg} / \mathrm{g})$} \\
\cline { 2 - 5 } $\begin{array}{l}\text { volume } \\
(\mathrm{mL})\end{array}$ & $\begin{array}{c}\text { Palmitic } \\
\text { acid }(\mathrm{C} 16: 0)\end{array}$ & $\begin{array}{c}\text { Stearic } \\
\text { acid } \\
(\mathrm{C} 18: 0)\end{array}$ & $\begin{array}{c}\text { Oleic acid } \\
(\mathrm{C} 18: 1)\end{array}$ & $\begin{array}{c}\text { Linoleic } \\
\text { acid } \\
(\mathrm{C} 18: 2)\end{array}$ \\
\hline 1.8 & $230.8 \pm 7.5$ & $26.9 \pm 0.7$ & $271.6 \pm 9.1$ & $99.6 \pm 3.2$ \\
2.0 & $241.6 \pm 0.4$ & $28.1 \pm 0.1$ & $283.0 \pm 0.7$ & $104.0 \pm 0.2$ \\
2.2 & $243.8 \pm 0.1$ & $28.4 \pm 0.2$ & $290.0 \pm 6.3$ & $106.8 \pm 2.3$ \\
\hline
\end{tabular}

Table 8. Uncertainty of repeatability $\left(\mathrm{U}_{\mathrm{r}}\right)$ and uncertainty of reproducibility $\left(\mathrm{U}_{\mathrm{r}}\right)$ of fatty acids determination in palm oil by GC-FID with $\mathrm{BF}_{3}$-methanol derivatization

\begin{tabular}{lccc}
\hline \multirow{2}{*}{ Fatty acid } & \multicolumn{2}{c}{$\mathrm{U}_{\mathrm{r}}(\mathrm{mg} / \mathrm{g})$} & \\
\cline { 2 - 3 } & \multicolumn{2}{c}{ Spiking concentration } & $\mathrm{U}_{\mathrm{R}}(\mathrm{mg} / \mathrm{g})$ \\
\cline { 2 - 3 } & $50 \mathrm{mg} / \mathrm{g}$ & $90 \mathrm{mg} / \mathrm{g}$ & \\
\hline Palmitic acid (C16:0) & 4.91 & 2.91 & 9.65 \\
Stearic acid (C18:0) & 1.84 & 3.22 & 1.40 \\
Oleic acid (C18:1) & 6.49 & 9.02 & 10.65 \\
Linoleic acid (C18:2) & 1.99 & 4.35 & 2.84 \\
\hline
\end{tabular}

\section{Uncertainty of Repeatability and Uncertainty of Reproducibility}

There are many sources of uncertainty in the analysis, two of which are uncertainty of repeatability $\left(U_{r}\right)$ and reproducibility $\left(U_{R}\right)$. $U_{r}$ and $U_{R}$ from the analysis of major fatty acids analysis in palm oil by GC-FID are presented in Table 8 .

\section{CONCLUSIONS}

The major fatty acids analysis in palm oil by using gas chromatography-flame ionization detection (GC-FID) has been evaluated and shown the acceptable results for stearic and linoleic acid analysis in terms of chromatographic precision, accuracy by recovery test, repeatability, intra-lab reproducibility and ruggedness. Due to the lower efficiency of fatty acid derivatization by $\mathrm{BF}_{3}$-methanol, the recovery values of palmitic and oleic acids were very low, less than $40 \%$. This method was considerably reliable for the analysis of less abundance fatty acids in palm oil, stearic and linoleic acids.

\section{ACKNOWLEDGEMENTS}

We thank Yane Regiyana for her technical help to use GC-FID at Department of Food Science and Technology, Faculty of Agricultural Engineering and Technology, Bogor Agricultural University, Indonesia.

\section{REFERENCES}

AOAC. (2012). Official Methods of Analysis of AOAC International (19 $9^{\text {th }}$ ed.). AOAC International Press, Maryland. Chapter 41, p 27-29 and Appendix K, p 8-10.

Ashraful, A.M., Masjuki, H.H., Kalam, M.A., Rahman, S.M.A., Habibullah, M. and Syazwan, M. (2014). Study of the effect of storage time on the oxidation and 
thermal stability of various biodiesels and their blends. Energy Fuels 28(2): 1081-1089.

Česnik, H.B. and Gregorčič, A. (2006). Validation of the method for the determination of dithiocarbamates and thiuram disulphide on apple, lettuce, potato, strawberry and tomato matrix. Acta Chimica Slovenica 53: 100104.

Gee, P.T. (2007). Analitycal characteristics of crude and refined palm oil and fractions. European Journal of Lipid Science and Technology 109(4): 373-379.

Gunstone, F.D. (2011). Vegetable Oils in Food Technology: Composition, Properties and Uses, Second Edition. Blackwell Publishing, Oxford. p 8.

Hallmann, C., Van aarssen, B.G.K. and Grice, K. (2008). Relative efficiency of free fatty acid butyl esterification, choice of catalyst and derivatisation Procedure. Journal of Chromatography A 1198-1199: 14-20.

Ichihara, K. and Fukubayashi, Y. (2010). Preparation of fatty acid methyl esters for gas-liquid chromatography. Journal of Lipid Research 51(3): 635-640.

JECFA. (2006). Analytical methods, Test Procedures and Laboratory Solutions Used by and Referenced in the Food Additive Specifications. Food and Agriculture Organization of The United Nations, Rome. p 23.

Kazusaki, M., Ueda, S., Takeuchi, N. and Ohgami, Y. (2012). Validation of analytical procedures by highperformance liquid chromatography for pharmaceutical analysis. Chromatography 33(2): 65-73.

Knapp, D.R. (1979). Handbook of Analytical Derivatization Reactions. Wiley-Interscience, Canada. p 148.

Knothe, G. and Kenar, J.A. (2004). Determination of the fatty acid profile by ${ }^{1} \mathrm{H}-\mathrm{NMR}$ Spectroscopy. European Journal of Lipid Science and Technology 106: 88-96.

Kumar, P.K.P. and Krishna, A.G.G. (2014). Physico-chemical characteristics and nutraceutical distribution of crude palm oil and its fractions. Grasas y Aceites 65(2): 1-12.

Liu, K.S. (1994). Preparation of fatty acid methyl esters for gas chromatographic analysis of lipids in biological materials. Journal of the American Oil Chemists' Society 71: 1179-1187.

Macedo, L.F.A., Lacerda, E.L.Q., Silva, R.D., Simionato, J.I., Pedrao, M.R., Coro, F.A.G. and De Souza, N.E. (2012). Implications of method chosen for analysis of fatty acids in meat: a review. American Journal of Agricultural and Biological Sciences 7(3): 278-284.

Martínez, M.V., De Quirós, A.R.B., Hernández, J.L. and Yusty, M. (2009). Fatty acid profile and total lipid content of chionoecetes opilio shells. The Open Food Science Journal 3: 93-97.

Milinsk, M.C., Matsushita, M., Visentainer, J.V., De Oliveira, C.C. and De Souza, N.E. (2008). Comparative analysis of eight esterification methods in the quantitative determination of vegetable oil fatty acid methyl esters (FAME). Journal of the Brazilian Chemical Society 19(8): 1475-1483.

Moreira, R.G., Castell-Perez, M.E. and Barrufet, M.A. (1999). Deep-Fat Frying: Fundamentals and Applications. Aspen Publication, Maryland.

Muhamad, N.A. and Mohamad, J. (2012). Fatty acids composition of selected Malaysian fishes. Sains Malaysiana 4(1): 81-94.

Omar, T.A. and Salimon, J. (2013). Validation and application of a gas chromatographic method for determining fatty acids and trans fats in some bakery products. Journal of Taibah University for Science 7: 56-63.

Orata, F. (2012). Derivatization Reactions and Reagents for Gas Chromatography Analysis. In: Mohd, M.A. (ed.). Advanced Gas Chromatography-Progress in Agricultural, Biomedical and Industrial Applications. Rijeka: InTech. p 83-108.

Paligova', J., Jori'Kova', L. and Cvengros, J. (2008). Study of FAME stability. Energy and Fuels 22: 1991-1996.

Parashar, A., Sinha, N. and Singh, P. (2010). Lipid contents and fatty acids composition of seed oil from twenty five pomegranates varieties grown in india. Advance Journal of Food Science and Technology 2(1): 12-15.

Petrovic', M., Kezic', N. and Bolanč, V. (2010). Optimization of the GC method for routine analysis of the fatty acid profile in several food samples. Food Chemistry 122: 285-291.

Ping, B.T.Y. (2013). Gas chromatography-flame ionization detector method for determination of carbon chain length distribution of palm-based fatty alcohol. Journal of Oil Palm Research 20: 36-43.

Squadrone, S., Ferro, G.L., Marchis, D., Mauro, C., Palmegiano, P., Amato, G., Poma Genin, E. and Abete, M.C. (2010) Determination of melamine in feed: Validation of a gas chromatography-mass spectrometry method according to 2004/882/CE regulation. Food Control 21(5): 714-718.

Sundram, K., Sambanthamurthi, R. and Tan, Y. (2003). Palm fruit chemistry and nutrition. Asia Pacific Journal of Clinical Nutrition 12(3): 355-362. 
Tong, L., Zhang, L., Yu, S., Chen, X. and Bi, X. (2007). Analysis of the fatty acids from Periploca sepium by GC-MS and GC-FID. Asian Journal of Traditional Medicines 2(3): 110-114.

Wang, P.G. (2008). High-Throughput Analysis in the Pharmaceutical Industry. CRC Press, Taylor and Francis Group, Boca Raton. p 174.
Wirasnita, R., Hadibarata, T., Novelina, Y.M., Yusoff, A.R.M. and Yusop, Z.A. (2013). Modified methylation method to determine fatty acid content by gas chromatography. Bulletin of the Korean Chemical Society 34(11): 32393242 . 